Article

\title{
Antecedents of Knowledge Interaction in the Sustainable Interdisciplinary Research Team: A Mixed Research Method
}

\author{
Xue Cheng ${ }^{1}$, Wei Pan ${ }^{2}$ and Qingpu Zhang ${ }^{1, *}$ \\ 1 School of Management, Harbin Institute of Technology, Harbin 150001, China \\ 2 School of Economics and Management, Harbin Engineering University, Harbin 150001, China \\ * Correspondence: zhangqingpu@hit.edu.cn; Tel.: +86-187-451-83549
}

Received: 13 April 2019; Accepted: 28 June 2019; Published: 1 July 2019

check for updates

\begin{abstract}
This paper mainly focuses on two questions: (1) Which factors mainly influence knowledge interaction in a sustainable interdisciplinary research team (SIDRT)? and (2) How are knowledge interaction processes structured in a SIDRT? This paper first defines the conception of knowledge interaction in a SIDRT from the complex system perspective. Then the model of key influencing factors in a SIDRT is constructed through grounded theory, including subjects' attributes, objects' characteristics, environment, and resources of knowledge interaction. Furthermore, we propose hypotheses and empirically validate our conceptual model. The combination of the two methods can strengthen the research conclusions from different angles. Finally, based on our qualitative and quantitative results, the theoretical and practical implications are discussed.
\end{abstract}

Keywords: knowledge interaction; sustainable interdisciplinary team; grounded theory; empirical research

\section{Introduction}

The term "sustainability" has caused a paradigm change in research methods. Due to these complexity, ambiguity, and dynamic exchanges, many problems, such as sustainable city system study [1], sustainable regulated river management [2], sustainable education, environments, business managements [3], and other sustainable and comprehensive problems often apply an interdisciplinary approach [4]. Therefore, many interdisciplinary (ID) teams have been assembled to solve these problems that are faced in the process of social development, and to ensure that multiple goals and multiple values are both successfully realized [5]. A notable international example is Stanford University Bio-x Interdisciplinary Research Program aiming to benefit human health and lower ecological footprints, which brings together over 600 teachers from all over the world [6]. It is clear that such program involves collaboration among medical doctors, scientists, and engineers. It also requires practitioners or team leaders to make decisions if there are gaps in opinions. This series of complex communications and decisions could explain why knowledge interaction is commonplace in a sustainable interdisciplinary research team (SIDRT). In particular, Hare states that the key to the success of a program, especially a complex program, lies in knowledge communication among team members [7]. Many studies have pointed out that knowledge interaction with high quality is the key to solving difficult and sustainable problems for a SIDRT [8,9].

To date, ID researchers have proposed many conceptual models to identify key antecedent conditions, intervening processes, and outcomes associated with team science initiatives and to explain the interrelationships among them. Many scholars focus on team performance and team innovation research [10-13]. However, the most debated aspect of interdisciplinarity is the process 
of "integration" [14-17]. Klein argues that there are four models of integration (common group learning, modeling, negotiation among experts and integration by leader) [18]. Bammer outlines three sets of characteristics (specialization, theoretical and methodological pillars, practical application) that will delineate integration and implementation sciences [19]. Hoffmann et al. combine three types of knowledge integration procedures (common group learning, negotiation among experts and integration by leader) and six categories of integration methods (definition, formulation, development, assessment, modeling and creation) to produce thematic synthesis reports [20]. However, a profound understanding of the challenges related to knowledge interaction, as it applies to ID research, is missing.

For sustainable ID research, it is important to characterize different kinds of dependencies and identify the interaction process that can be used to manage teams well [21]. Over the past decade, a variety of work has explored the various influencing factors of knowledge interaction for a SIDRT, including personal and structural characteristics [22], team leader behavior [23] and team climate [24]. In the aspect of knowledge interaction process, scholars mainly hold the two opposite perspectives, knowledge divergence [25] and knowledge convergence [26]. Researchers generally believe that shared ideas can stimulate other group members to think of other ideas or categories of ideas, further enhance the team creativity $[27,28]$. Inversely, others hold that knowledge convergence process has been conceptualized as a process of convergent decision-making that takes place after ideas are generated to improve the quality of the group's creative output [29]. Although prior studies are insightful, they are fairly fragmented and mainly focus on single factor or process. Thus, it is necessary to integrate the processes of knowledge interaction and explore its influencing factors from a holistic perspective to guide SIDRTs towards sustainable development.

Hence, the study is concerned with the following two questions:

1) Which factors mainly influence knowledge interaction in SIDRTs?

2) How are knowledge interaction processes structured in SIDRTs?

To address these questions, we first identity key influencing factors of SIDRTs using grounded theory. Secondly, we use regression analysis to analyze the mechanism of the influence factors on knowledge interaction and the internal association of knowledge divergence and convergence. Finally, we discuss theoretical and practical implications based on conceptual and empirical work of this paper. The remainder of this paper is organized as follows. Section 2 discusses knowledge interaction of SIDRTs from a complex system perspective. In Sections 3 and 4, a conceptual model of influencing factors is generated through grounded theory. In Sections 5 and 6, hypotheses are proposed and tested. The results are detailed in Section 7. Finally, Section 8 contains the discussion and our conclusions, including theoretical and practical implications, limitations, and future research directions.

\section{Conceptual Framework}

\subsection{Interdisciplinary Research}

Of all the definitions that have appeared, multidisciplinarity and interdisciplinarity are the most commonly identified processes of cross-disciplinary research, which have been described by Rosenfield [30]. Multidisciplinarity is a conglomeration of disciplinary components, in which team members remain their own concepts or methods of their respective fields firmly. In contrast to multidisciplinarity, inderdisciplinarity involves the integration of perspectives, concepts, theories, and methods from different fields, emphasizing an interactive process.

In the context of this research, our focus is mainly on interdisciplinarity. Following the related literature $[22,24,31]$, we refer to interdisciplinarity as knowledge interaction among team members of different disciplines. The "discipline" here refers to having different academic backgrounds. The differences in skills and job experiences are reflected in the team members themselves. Through the collision between various paradigms, borrowing of theories and methods between disciplines, team members will generate new ideas, methods, and work jointly to address a common research 
problem. According to this definition, the core challenge of interdisciplinary is to integrate knowledge of different fields.

\subsection{Farming Research for Knowledge Interaction}

A common way relating ID research is through the science of team science (SciTS). It aimed at examining the processes of team's organization, communication and conduction [32]. This field needs multilevel and mixed-methods to integrate different disciplines and guide effective policy on team sciences [33]. From a macro level, structural elements of collaboration, such as team size, organization and participant experiences, are connected to internal and external environment of the team [34]. From a micro level, perceived interpersonal collaboration processes and intrapersonal characteristics are predictive for research productivity [35]. In general, the SciTS has been enriched by substantial of knowledge.

However, for SIDRTs, knowledge interaction is very important to the process of communication, which is the core of knowledge management. Through knowledge interaction, team members can communicate in depth between disciplines to address complex problems and accelerate innovations. Hence, we use the term "knowledge interaction" as a process or activity, in which the team members use knowledge communication, knowledge sharing, knowledge collision, knowledge integration of critical information, scientific and technological knowledge, and skills to achieve technical innovation and system innovation [36].

In contrast to other teams, knowledge interaction in SIDRTs has its own characteristics:

1) Stronger dynamics

Since the tasks to be completed by SIDRTs are innovative and challenging, the process of knowledge interaction among team members cannot be predicted in advance. In addition, interdependence between interdisciplinary team members is also unpredictable due to incomplete task information. Members cannot forecast who will interact with them next time and what kind of thinking collisions will occur. Furthermore, the introduction of new technologies, new equipment, and new members requires team members to constantly adjust and adapt to higher requirements.

2) Cyclical

Due to the differences between team members' disciplines and experiences, both sides of knowledge interaction will repeat the loop of "knowledge expression $\rightarrow$ knowledge interpretation $\rightarrow$ knowledge divergence $\rightarrow$ knowledge convergence $\rightarrow$ knowledge supplement" until they find new ideas and solve complex problems. In the process of cycle, the whole knowledge of the team gradually approaches the optimal solution to the problem.

3) More complex uncertainty

Since the team is conducting sustainable research, the interaction period is long, and the interaction results are uncertain. On the one hand, the source of knowledge is uncertain, due to the randomness of knowledge information acquired by team members, and the ambiguity and inconsistency caused by team members' cognitive differences on knowledge understanding. On the other hand, personnel adjustment and changes in the cognition and behavior of team members can influence the knowledge interaction environment that other team members face.

In total, knowledge interaction spans a large range of dimensions and scales, including team members, environment, and kinds of resources. To facilitate knowledge interaction among team members, the development of shared mental models [36] is crucial. Shared mental models are organized mental representations of the key elements (including related tasks, equipment, work relationships and situations) within a team's relevant environment [37]. They are also the premise of knowledge interaction and help the teams in the communication, problem-solving, and decision-making needed to develop a research plan [36]. In addition, under the premise that various interest mechanisms and trust 
mechanisms are guaranteed, knowledge interaction between elements is sometimes a self-organization form, which is the emergence of complex behavior. These properties of knowledge interaction are well reflected from the perspective of system science. Hence, to look at the whole of knowledge interaction and its relationship to the parts, we apply system science framework to address this issue.

\subsection{Knowledge Interaction in SIDRTs from a Complex System Perspective}

The solution to the major comprehensive problems that plague all human beings, such as social, environment, ecology and energy issues, increasingly requires the collaboration of people from different disciplines. Thus, sustainable interdisciplinary research team is regarded as a powerful means to hit the targets. To explicate how team members interact and achieve their objectives, we introduce complex systems theory.

"System" is one of the most basic concepts in system science. It is an organic whole with specific function that consists of interacting and interdependent parts (elements). The integrity of the system structure is one of the most significant features. As a whole, the system has the functions and properties that independent elements do not have. Xuesen proposed combining system science with thinking science for interdisciplinary research [38], guiding us to apply the concepts and methodology of systems engineering and thinking science in the process of knowledge management and innovation to deal with the application and innovation of knowledge. More recent reviews of team research reflect the emerging perspective of work teams as dynamic, emergent, and adaptive entities embedded in a multilevel system $[39,40]$, i.e., teams are complex dynamic systems that exist in a context, develop as members interact over time, and evolve and adapt as situational demands unfold [11]. Therefore, we will analyze the knowledge interaction process of interdisciplinary team based on complex systems theory. Knowledge interaction is a dynamic and complex process in a SIDRT, which could be viewed as a complex system (see Figure 1). Then we will analyze it from the following aspects.

First, the most basic units of knowledge interaction are elements and associations. The main elements are team members who participate in the knowledge interaction. Any members (ordinary members or team leader) who is related to the task can express their own thoughts, regardless of the position or status. Team members have an independent knowledge structure, and can independently sense, receive and process the surrounding knowledge information to achieve the goal of knowledge integration [41]. According to the needs of the team's tasks, the elements of knowledge interaction are not static, and the personnel of the knowledge interaction will be constantly adjusted as the task progresses. On the other hand, the association in the system is knowledge interaction, which makes the knowledge interaction system develop towards the optimal solution.

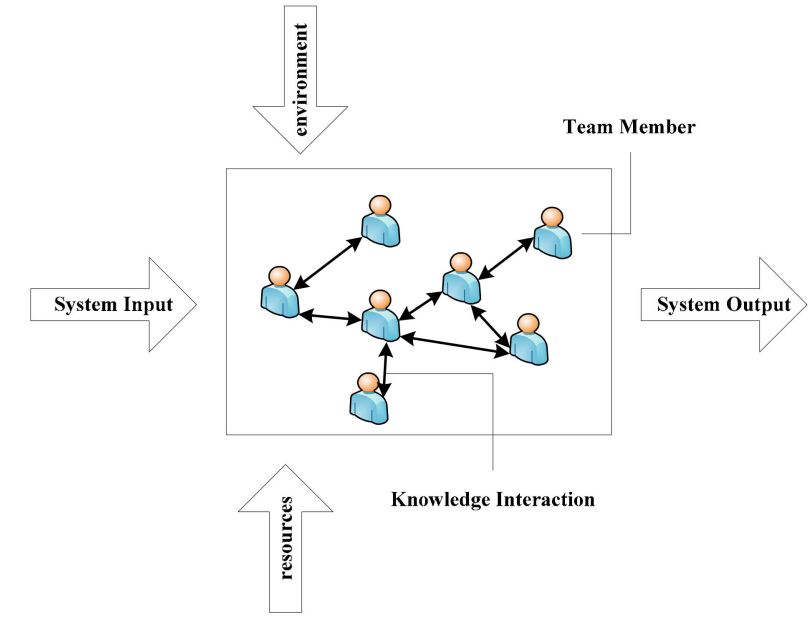

Figure 1. Knowledge interaction in a SIDRT from a complex system perspective. 
Second, knowledge interaction is closely related to the environment in which it is located, and cannot exist independently from the environment [42]. Environment of knowledge interaction can be divided into the internal and the external environment. The internal environment is mainly composed of the relevant interests and trusts formed by the knowledge interaction subjects. The external environment is mainly composed of the network environment, cultural environment, and academic environment where a SIDRT is located. Different types of environments play different roles in the process of knowledge interaction. A good internal environment is conducive to promoting the knowledge exchange of knowledge interaction subjects. The external network environment can provide more knowledge interaction channels and resources for knowledge interaction subjects. The cultural environment and academic environment can create an appropriate cultural and academic atmosphere for interdisciplinary teams, and are more conducive to knowledge interaction among interactive subjects.

Third, emergence is the most important feature of knowledge interaction system [43], which presents a dual emergence feature in Figure 2. Emergence is first reflected in the subjects of knowledge interaction. Through the multi-directional knowledge collision, the knowledge interaction subject itself will emerge new ideas or knowledge when the knowledge accumulates to a certain extent. In addition, there will be an emergence among knowledge interaction objects. The knowledge in the objects emerges new knowledge structure through the transfer, integration, and mutation. Furthermore, the team will emerge as a whole. After the emergence of the knowledge interaction subjects and the knowledge interaction objects reach a certain level, the interdisciplinary team will emerge and show the unique characteristics of the whole, such as the ability to solve problems and knowledge innovation.

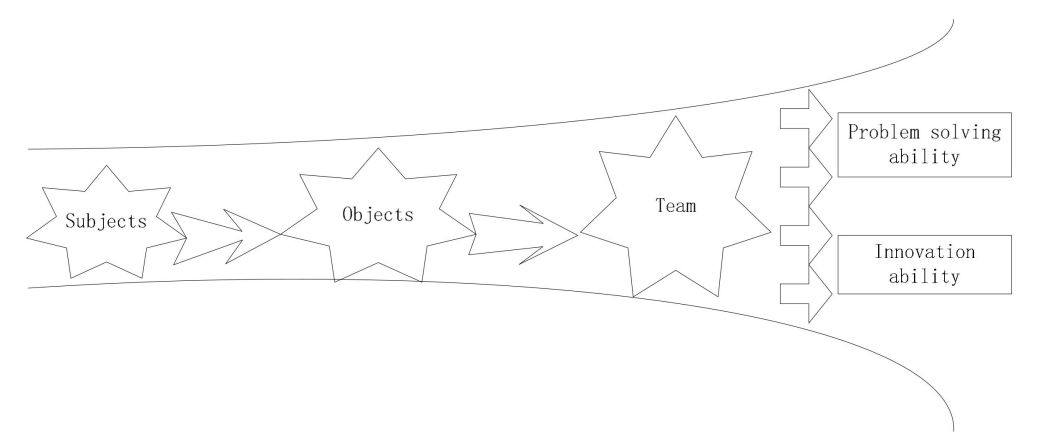

Figure 2. Emerging model of knowledge interaction in a SIDRT.

In conclusion, knowledge interaction in SIDRTs is based on the team members as the elements, through the exchange and sharing of knowledge, and forms an organic whole with certain knowledge functions to solve complex problems and innovate in the network environment, technical environment, and policy environment.

\section{Research Methodology and Research Design}

\subsection{Mixed Research Method}

Mixed research method [44-47] is a research method that combines quantitative and qualitative data in a same study. This method has been systematically and formally developed for at least 20 years. The advantage of this method is to strengthen the research conclusions from different angles. According to this purpose, this paper will combine the grounded theory method with the empirical research method. In the first stage, we use the grounded theory method to construct a conceptual model of knowledge interaction. The respondents for this study came from four SIDRTs. In the second stage, this paper uses empirical research method to validate the credibility and persuasiveness of the proposed conceptual model, and the samples were taken from SIDRTs in China. The combination of the two methods provides confirmation to the conceptual model of knowledge interaction from different angles. 
It can ensure a well-grounded scientific framework for the empirical undertakings consistent with the assumed objectives.

\subsection{Ethical Approval Statement}

All subjects gave their informed consent for inclusion before they participated in the study. The study was conducted in accordance with the management scientific research methods and the Academic Research Ethics of School of Management, Harbin Institute of Technology. Every effort was made to protect people's privacy from being violated. All participants were informed of the purposes of the study. Written informed consent was obtained from all participants before the study commenced.

\subsection{Grounded Theory}

Grounded theory [48] is a qualitative research method first proposed by Glaser and Strauss in 1967. Through open coding, axial coding, and selective coding of the original data, this method gradually enhances the abstract relationships between categories from the bottom up, and links all categories together to form theory. Grounded theory is more suitable for research that has theoretical blanks or that the existing theoretical system is not perfect. Although there has been a large amount of literature on knowledge management in different contexts [49-51], there is little research on knowledge interaction in SIDRTs. Knowledge interaction in the interdisciplinary team is very different from that of the ordinary team, and the knowledge fusion and matching degree of the team are higher. To clarify the complex antecedents of knowledge interaction from different angles, this paper will use grounded theory to develop this research.

\subsection{Research Design}

We selected four representative interdisciplinary teams from China, all of which are long-term engaged in sustainable research. The basic information of the interviewed team is shown in Table 1 (In order not to reveal the team's information, we hide the teams' name).

Table 1. Basic information of the interviewed team.

\begin{tabular}{|c|c|c|c|}
\hline Interviewed Team & Engaged Research & Number & Professional Background of Members \\
\hline 1 & $\begin{array}{l}\text { Perceptual computational } \\
\text { heart simulation study }\end{array}$ & 18 & Computer, mathematical, biology \\
\hline 2 & Competitive robot & 67 & $\begin{array}{l}\text { Electromechanical, automation, electric, } \\
\text { computer, software }\end{array}$ \\
\hline 3 & Medical material research & 25 & Physical, medicine, biology \\
\hline 4 & Small satellite research & 83 & $\begin{array}{l}\text { Aircraft design, Information and } \\
\text { communication engineering, control } \\
\text { theory and application, Human-machine } \\
\text { environment engineering }\end{array}$ \\
\hline
\end{tabular}

Using the method of theoretical sampling, the number of samples is determined according to the theoretical saturation required by the grounded theory, i.e., the sample is extracted until the newly drawn respondent no longer provides new and important information [52]. In the end, a total of 31 respondents were selected for this interview. The basic data are shown in Table 2.

This study was conducted in a combination of in-depth personal interviews and focus group interviews. Each interview had three members of our research team, including two interviewers and one recorder. In total, there are 19 persons conducting in-depth personal interviews, and each interview took about $30-40 \mathrm{~min}$. Focus group interviews were organized 4 groups with 3 persons in each group, and each interview took about 40-60 $\mathrm{min}$. In the preparation stage of the interview, we contacted the respondents by phone or WeChat, appointed the time and place of the interview, and explained the connotation of knowledge interaction to the interviewees in advance. At the beginning of the formal interview, we explained the meaning of knowledge interaction to the respondents again, to ensure that each respondent can understand our research topic. The interviews in this study are 
mainly open-ended interviews, and the interviews mainly focus on the following issues: (1) How do you interact with other discipline members in your team? (2) What do you think are the main factors affecting knowledge interaction? (3) How is the atmosphere of your team's knowledge interaction? (4) Do you have some experiences in knowledge interaction? What are they? (5) Do you think knowledge interaction is helpful to you or your team?

Table 2. The distribution of respondent's characteristics.

\begin{tabular}{cccc}
\hline Term & Content & Frequency & Percentage (\%) \\
\hline \multirow{2}{*}{ Sex } & Male & 23 & 74.2 \\
& Female & 8 & 25.8 \\
\hline \multirow{4}{*}{ Age } & $<25$ & 4 & 12.9 \\
& $25-29$ & 14 & 45.2 \\
& $30-39$ & 9 & 29 \\
& $40-49$ & 3 & 9.7 \\
\multirow{2}{*}{ Education } & $50-59$ & 0 & 0 \\
& $60<$ & 1 & 3.2 \\
\hline \multirow{2}{*}{ Position } & Master & 11 & 35.5 \\
& PhD & 20 & 64.5 \\
\hline
\end{tabular}

We recorded the interview sound with the consent of the respondents. In the course of the interview, we tried to guide the respondents to give some examples of knowledge interaction, and further followed up on the concepts captured around the outline. In addition, we gradually adjusted the interview content and focus according to the effect of the interview, so as to maximize the insight into the psychological changes of the respondents.

\section{Research Data Analysis}

\subsection{Open Coding}

Open coding is the process where the data are broken down into discrete parts, closely examined, compared for similarities and differences, and questions are asked about the phenomena reflected in the data [53]. To reduce the subjective bias of the researcher, we tried to use the original words of the respondents as a label to extract the initial concepts in the coding. To ensure the validity of the code, we asked two members of our research team to independently code to determine the initial concepts and categories. For inconsistent concepts or categories, we modified or deleted them combined with the opinions of experts in the field to improve the objectivity of coding. We obtained a total of more than 450 original sentences and corresponding initial concepts. Since the initial concepts are complex and have a certain degree of intersection, we eliminate those nonsignificant (the frequency of occurrence is less than two) and inconsistent initial concepts when categorizing. Finally, 30 concepts, 9 categories, corresponding relationships of categories are obtained, as shown in Table 3. The words in parentheses at the end of each sentence indicate the initial concept coded from the original statement. 
Table 3. Categorization of opening coding.

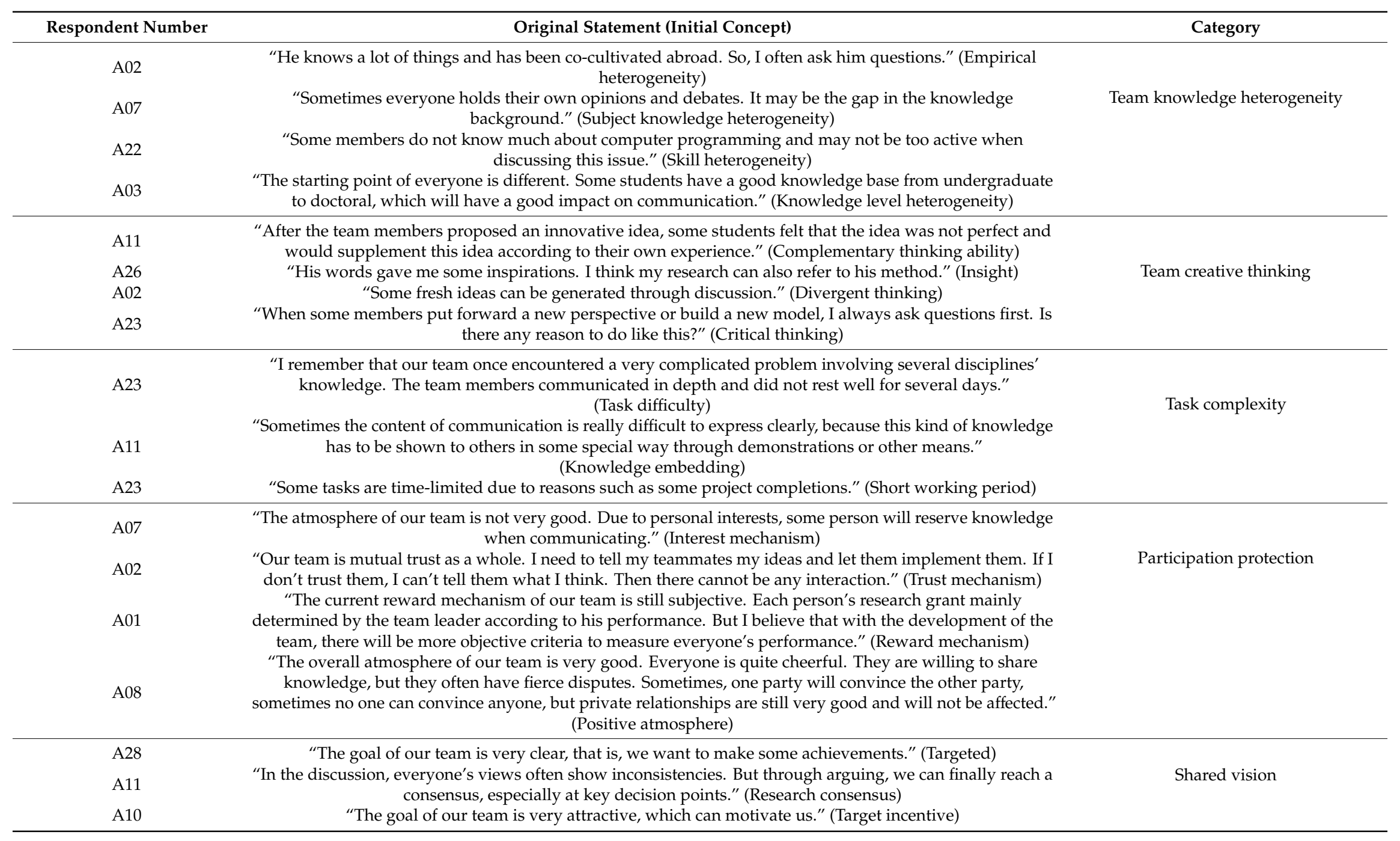


Table 3. Cont

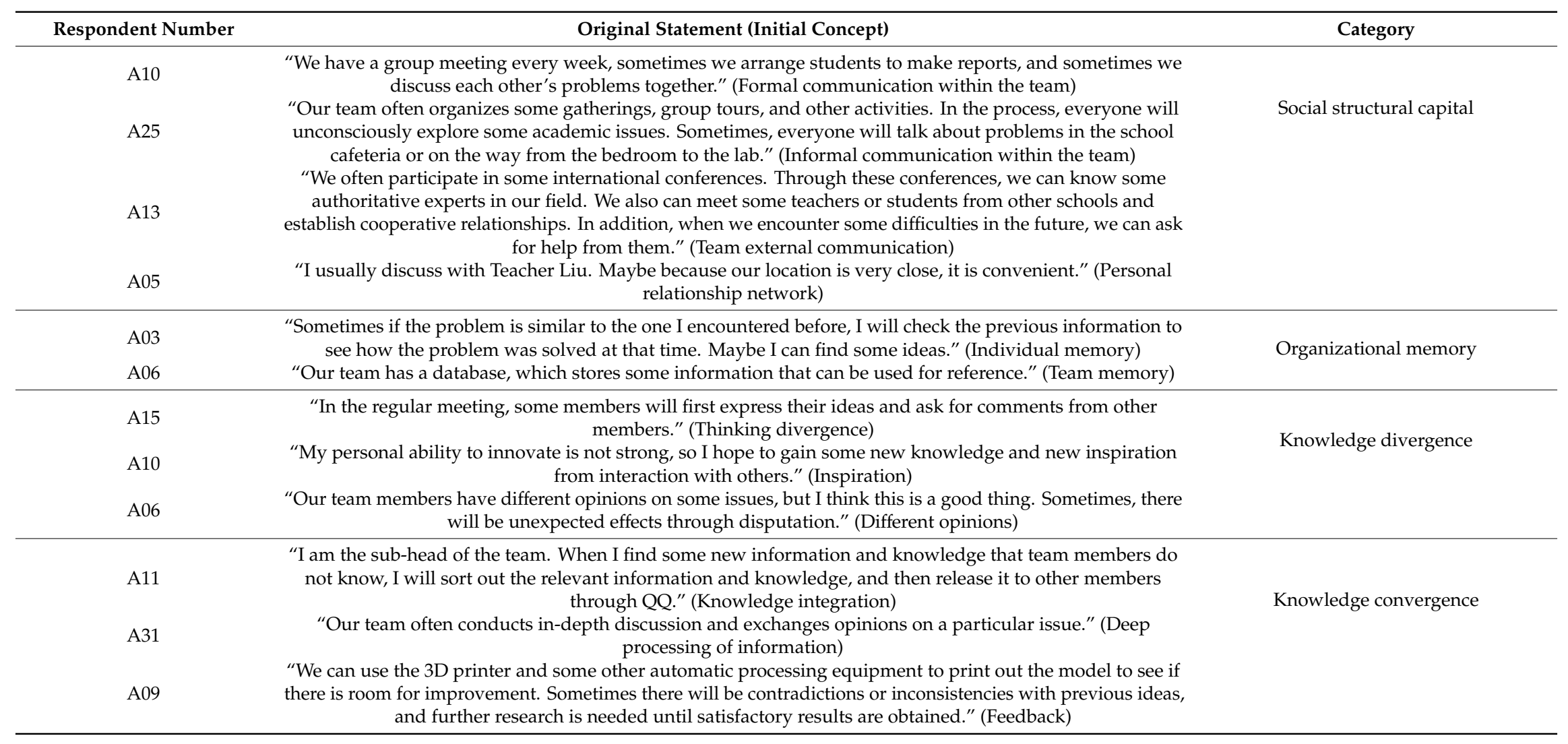




\subsection{Axial Coding}

Axial coding is the process of discovering the potential logical connections among categories, and developing the main categories [53]. In other words, the task of axial coding is still to develop categories, but only one step closer to the development of its nature and dimensions. Through repeated thinking and analysis of the initial concepts, this study summarizes 5 main categories. The categories and their corresponding open coding categories are shown in Table 4.

Table 4. Main categories formed by axial coding.

\begin{tabular}{|c|c|c|}
\hline Main Category & Category & Relationship Connotation \\
\hline \multirow[t]{2}{*}{ Subject factor } & Team knowledge heterogeneity & $\begin{array}{l}\text { Knowledge heterogeneity affects the way in which } \\
\text { knowledge interaction subjects solve problems }\end{array}$ \\
\hline & Team creative thinking & $\begin{array}{l}\text { Creative thinking affects the way in which knowledge } \\
\text { interaction subjects think about problems }\end{array}$ \\
\hline Object factor & Task complexity & $\begin{array}{c}\text { The inherent attributes of the task affect } \\
\text { knowledge interaction }\end{array}$ \\
\hline Environment factor & $\begin{array}{l}\text { Participation protection } \\
\text { Shared vision }\end{array}$ & $\begin{array}{l}\text { Participation protection affects knowledge interaction } \\
\text { Shared vision affects knowledge interaction }\end{array}$ \\
\hline \multirow{2}{*}{ Resource factor } & Social structural capital & $\begin{array}{c}\text { Social structural capital helps to get more } \\
\text { information resources }\end{array}$ \\
\hline & Organizational memory & Organizational memory affects knowledge interaction \\
\hline \multirow[t]{2}{*}{ Knowledge interaction } & Knowledge divergence & $\begin{array}{l}\text { Knowledge divergence is an important process of } \\
\text { knowledge interaction }\end{array}$ \\
\hline & Knowledge convergence & $\begin{array}{c}\text { Knowledge convergence is an important process of } \\
\text { knowledge interaction }\end{array}$ \\
\hline
\end{tabular}

\subsection{Selective Coding}

Selective coding is to extract the "core category" from the main categories, and form a multi-chord logical relationship centered on the "core category", which can be called the "story line" [53]. After the completion of the "story line", a new substantive theoretical framework has been developed. In this study, the typical relationship structures of the main category are shown in Table 5.

Table 5. Typical relational structures of main categories.

\begin{tabular}{cc}
\hline Typical Relational Structure & The Connotation of the Relationship Structure \\
\hline Subject factor $\rightarrow$ Knowledge interaction & Subject factor is the key antecedent of \\
knowledge interaction
\end{tabular}

This study identifies the core category of antecedents of knowledge interaction in SIDRTs. The "story line" of the core category can be expressed that subject factors, object factors, environmental factors, and resource factors have important impact on the knowledge interaction of SIDRTs. Based on this storyline, this study establishes an influencing factor model of knowledge interaction in the interdisciplinary team, as shown in Figure 3. 


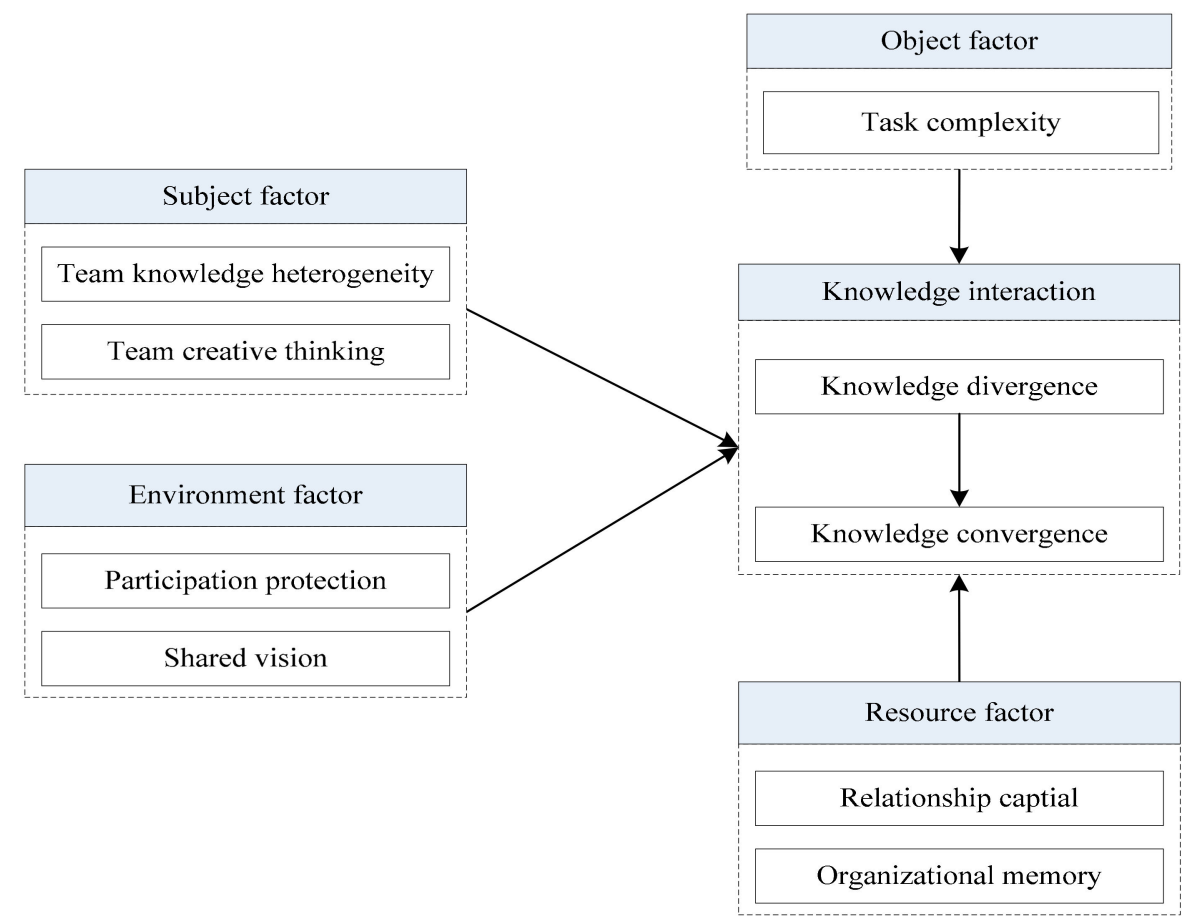

Figure 3. Influencing factor model of knowledge interaction in SIRT.

\subsection{Theoretical Saturation Test}

This study used the remaining interview records randomly reserved to test whether the model has reached theoretical saturation. The results show that no new key categories and relationships other than the five main categories in the model are obtained, and no new constituent factors are found in the five main categories. Therefore, it can be considered that the above model achieves theoretical saturation.

\section{Model Interpretation and Assumptions}

\subsection{Knowledge Divergence and Knowledge Convergence}

Based on the previous model, the knowledge interaction process in SIDRTs mainly includes two core sections: knowledge divergence and knowledge convergence. From a cognitive perspective, creation is a process of thinking divergence and convergence. Mordan and Ghoshal pointed out that the creation of any resource, including knowledge, has to undergo exchange and integration [54]. In the process of knowledge divergence, team members can share some knowledge, ideas, etc., and can also inspire members to generate new ideas based on existing knowledge. On the other hand, knowledge convergence is the process of team members using scientific methods and logical integration thinking to integrate knowledge from different sources, different disciplines, and different levels. Only through the effective knowledge divergence and understanding the individual knowledge can we establish the association between knowledge based on the characteristics of knowledge, and further realize the emergence of individual knowledge into team knowledge. We therefore put forward the following hypothesis:

H1. Knowledge divergence has a positive impact on knowledge convergence.

\subsection{Knowledge Interaction Subject and Knowledge Interaction}

The main characteristics of members in a SIDRT are reflected in knowledge heterogeneity and creative thinking ability. Compared with the ordinary team, the biggest advantage of the SIDRT is that the team can gather people from different professional backgrounds, so that the information 
resources of the team are more abundant, and members can think about the problem from different angles [55]. Members with different knowledge types and knowledge backgrounds can generate more innovative ideas, which can promote the knowledge divergence of the team [26]. However, disciplinary differences also can lead to communication problems due to specialized training and terminology and to differences in what is taken for granted by individuals in a given specialty [56]. Especially in the knowledge convergence phase, if team members stick to their own opinions, it is difficult to integrate good ideas together to solve problems.

Creative thinking emphasizes the divergence and transformation of thinking. When a member's idea is stimulated by the idea of another member, a new idea will be generated [57]. Prior research has also shown that shared ideas can stimulate other group members to think of other ideas or categories of ideas [26,27]. On the other hand, team members with creative thinking are often good at integrating cross-category and cross-disciplinary knowledge, information or experience to get a creative new idea [58]. This will help team members build and re-build knowledge in the process of knowledge interaction and promote team knowledge innovation. We therefore put forward the following hypotheses:

H2a. Team knowledge heterogeneity has a positive impact on the knowledge divergence.

H2b. Team knowledge heterogeneity has a negative impact on the knowledge convergence.

H3a. Team creative thinking has a positive impact on the knowledge divergence.

H3b. Team creative thinking has a positive impact on the knowledge convergence.

\subsection{Knowledge Interaction Object and Knowledge Interaction}

Task complexity is the main attribute of knowledge interaction objects in SIDRTs, including task difficulty, knowledge embedding, and knowledge implicitness. Nickerson and Zenger argues that a problem's complexity influences the optimal method of solution search and the optimal means of organizing that search [59]. Some studies have confirmed that task complexity has an important relationship with the generation of creative ideas [60-62]. Through complex tasks, the creative thinking of interdisciplinary team members will be stimulated. Team members will change the original negative communication attitude, actively mobilize various resources, and constantly search and learn knowledge and experience inside and outside the team [63], which ensure the effective divergence and aggregation of knowledge, and the successfully completion of task. Therefore, we propose the following hypotheses:

H4a. Task complexity has a positive impact on the knowledge divergence.

H4b. Task complexity has a positive impact on the knowledge convergence.

\subsection{Knowledge Interaction Environmentand Knowledge Interaction}

Based on the results of the previous qualitative study, a SIDRT's knowledge interaction environment mainly includes team participation guarantee and shared vision. When team members engage in knowledge interaction, the atmosphere created by the team must enable team members to easily express their opinions, and give or receive feedback from each other in order to achieve team innovation [64]. The study also found that only when team members feel they are in a safe, fair, and relaxed environment, they are willing to share their experiences and perceptions $[65,66]$. In addition, the interpersonal interactions of team members in daily work can enhance the sense of belonging and team identity, and play an important role in alleviating internal conflicts and strengthening team cohesion [67].

Shared vision is defined as the degree to which team members have a clear picture of, and agree upon, the goals of the team [68]. For SIDRTs, team goals may be more diffused, due to the different functional frameworks within which the team members operate [69]. Fay et al. argue that having a shared vision provides the "glue" that holds an interdisciplinary team together [13]. If the 
members perform well on a shared vision that the team has identified, then more members will hold the vision more firmly and are more willing to work harder [70]. We therefore put forward the following hypotheses:

H5a. Participation guarantee has a positive impact on the knowledge divergence.

H5b. Participation guarantee has a positive impact on the knowledge convergence.

H6a. Shared vision has a positive impact on knowledge divergence.

H6b. Shared vision has a positive impact on knowledge convergence.

\subsection{Knowledge Interaction Resourceand Knowledge Interaction}

Knowledge interaction resources in SIDRTs mainly include social structural capital and organizational memory. Social capital is defined as "the sum of actual and potential resources embedded within, available through, and derived from the network of relationships possessed by an individual or social unit" [71]. According to Nahapiet and Ghoshal social capital can be divided three dimensions: structural, relational, and cognitive [71]. This study mainly focuses on the structural capital, which reflected in a team's social network structure. The stronger the internal network of team, the higher the communication and informal interaction among members, which in turn helps increase the opportunities for interaction to understand each other's needs and share knowledge. In addition, team members through the network ties can exchange information to integrate knowledge successfully [72]. In addition, the structural capital is very important to knowledge convergence when teams communicated through lean digital networks or face-to-face communication [73].

Organizational memory is both an important source of knowledge within the organization and an important factor driving organizational innovation [74]. Organizational memory accumulated through team members' experiences constitutes a valuable knowledge asset and acts as a source of competitive advantage [75]. In addition, organizational memory cannot be lost with the departure of team members. It can not only help the team make decisions for the current team tasks, but also help new team members understand the teamwork as soon as possible and promote the team's knowledge interaction. Further organizational memory can increase team efficiencies and decrease possible repeated errors [76]. Hence, we hypothesize:

H7a. Social structural capital has a positive impact on the knowledge divergence.

H7b. Social structural capital has a positive impact on the knowledge convergence.

H8a. Organizational memory has a positive impact on the knowledge divergence.

H8b. Organizational memory has a positive impact on the knowledge convergence.

\section{Empirical Research}

\subsection{Sample and Data Collection}

We choose members of SIDRTs in the research universities as sample, which are different from the four teams interviewed previously. In total, 700 questionnaires were administered, 620 were returned, and 172 were excluded due to invalid responses. Therefore, the final sample was 448 . The valid questionnaire response rate was $64 \%$. There were 204 males and 244 females. $97 \%$ of respondents are under 35 years old. And the respondents are mainly master's degree $(81.7 \%)$. The details are shown in Table 6. 
Table 6. Distribution of sample characteristics.

\begin{tabular}{cccc}
\hline Item & Content & Frequency & Percentage (\%) \\
\hline \multirow{2}{*}{ Sex } & Male & 204 & 45.5 \\
& Female & 244 & 54.5 \\
\hline \multirow{3}{*}{ Age } & $<24$ & 194 & 43.3 \\
& $25-29$ & 210 & 46.9 \\
& $30-34$ & 34 & 7.6 \\
& $35-39$ & 10 & 2.2 \\
\hline \multirow{2}{*}{ Education } & Master & 366 & 81.7 \\
& PhD and above & 82 & 18.3 \\
\hline
\end{tabular}

\subsection{Measures}

We measure all the constructs in this study based on scales developed in previous research studies. Team knowledge heterogeneity is measured using scale developed by Tortoriello [77], including differences in expertise, values, and cognition. Team creative thinking is measured by three items: idea sharing, idea complementarity, and idea integration, taken from Jiang [78]. Task complexity is measured by a three-item scale used by Campbell [79]. The participation guarantee scale is derived from team atmosphere model by Anderson and West [80]. Shared vision is also from team atmosphere model. Social structural capital is operationalized by three scaled items adopted from Jiang et al. [81]. In addition, three items for organization memory is adopted from Hanvanich [82] and Camison and Villar-Lopez [83]. Knowledge interaction, the dependent variable, is measured by knowledge divergence and knowledge convergence, in accordance with the scales used by Bock [84]. Five-point Likert scale were used for all measures (ranging from $1=$ strongly disagree to $5=$ strongly agree). The measures for all constructs are shown in Table 7.

Table 7. Constructs and Measurement Scales.

\begin{tabular}{|c|c|c|}
\hline Construct & Item Number & Item \\
\hline \multirow{3}{*}{ Team knowledge heterogeneity } & TKH1 & Expertise varies widely among team members. \\
\hline & TKH2 & Values vary widely among team members. \\
\hline & TKH3 & $\begin{array}{l}\text { Team members have a great understanding difference on how to } \\
\text { accomplish tasks. }\end{array}$ \\
\hline \multirow{3}{*}{ Team creative thinking } & TCT1 & We can share ideas frequently at work. \\
\hline & TCT2 & We can complement ideas frequently at work. \\
\hline & TCT3 & We can integrate ideas effectively at work. \\
\hline \multirow{3}{*}{ Task complexity } & TC1 & TC1. Teamwork is highly challenging. \\
\hline & TC2 & Teamwork needs to open up new areas and content constantly. \\
\hline & TC3 & Team work often requires designing new work processes and methods. \\
\hline \multirow{3}{*}{ Participation guarantee } & PG1 & We can understand and accept each other. \\
\hline & PG2 & We can share information with each other. \\
\hline & PG3 & We can feel that our team is a whole. \\
\hline \multirow{3}{*}{ Shared vision } & SV1 & We are in agreement on the overall goal of the team. \\
\hline & SV2 & $\begin{array}{c}\text { Our team's goals are clear and pioneering and can inspire everyone's } \\
\text { innovation drive. }\end{array}$ \\
\hline & SV3 & We can reach consensus on key decisions of the team. \\
\hline \multirow{3}{*}{ Social structural capital } & SSC1 & Our team often holds workshops. \\
\hline & SSC2 & $\begin{array}{l}\text { We often talk about work in informal places such as cafeterias } \\
\text { or lounges. }\end{array}$ \\
\hline & SSC3 & $\begin{array}{l}\text { Our team often organizes informal events such as dinners } \\
\text { and networking. }\end{array}$ \\
\hline \multirow{3}{*}{ Organization memory } & OM1 & $\begin{array}{c}\text { The knowledge and information of our team is reflected in the } \\
\text { organizational structure, systems, and processes. }\end{array}$ \\
\hline & OM2 & The culture of our team contains ideas and ways of doing things. \\
\hline & OM3 & $\begin{array}{c}\text { Our team uses papers, patents, and licenses as an effective way to } \\
\text { store knowledge. }\end{array}$ \\
\hline
\end{tabular}


Table 7. Cont.

\begin{tabular}{|c|c|c|}
\hline Construct & Item Number & Item \\
\hline \multirow{3}{*}{ Knowledge divergence } & KD1 & \multirow{3}{*}{$\begin{array}{l}\text { Our team members often share ideas and inspirations. } \\
\text { Our team members often share work experience or knack. } \\
\text { If other team members request, I will provide the knowledge source or } \\
\text { insider that I know. }\end{array}$} \\
\hline & KD2 & \\
\hline & KD3 & \\
\hline \multirow{3}{*}{ Knowledge convergence } & $\mathrm{KC1}$ & \multirow{3}{*}{$\begin{array}{l}\text { Team members can effectively reorganize shared knowledge. } \\
\text { Team members can effectively solve the problems encountered through } \\
\text { coordination. } \\
\text { Team members can clarify the hard-to-express knowledge, } \\
\text { communicate, and learn mutually. }\end{array}$} \\
\hline & KC2 & \\
\hline & $\mathrm{KC} 3$ & \\
\hline
\end{tabular}

\subsection{Data Analysis}

We conducted a statistical check for common method bias with Harman's single factor test [85]. By using unrotated method of exploratory factor analysis, we obtained the interpretation variation of one fixed factor was $29.11 \%$. The results showed that one-factor solution failed to account for most of the total variation.

In this research, Cronbach's $\alpha$ is used to analyze the reliability of each scale, as shown in Table 8. The Cronbach's $\alpha$ of the scale is greater than 0.7 , indicating that the data of this study has considerable credibility. Exploratory factor analysis was used to test the validity of the measurement model. The results showed a good validity for the model: KMO (Kaiser-Meyer-Olkin) is 0.89, $\chi^{2}(528)=3284.379, p<0.001$. The normalized factor loading of all items is greater than 0.5 , and the average variance extraction (AVE) is also greater than 0.5 .

Table 8. Testing of reliability and validity.

\begin{tabular}{cccc}
\hline Item & Cronbach's $\alpha$ & AVE & Factor Loading \\
\hline Team knowledge heterogeneity & 0.870 & 0.796 & $0.877-0.901$ \\
Team creative thinking & 0.771 & 0.689 & $0.819-0.836$ \\
Task complexity & 0.728 & 0.649 & $0.787-0.831$ \\
Participation guarantee & 0.704 & 0.629 & $0.783-0.811$ \\
Shared vision & 0.703 & 0.633 & $0.782-0.809$ \\
Social structural capital & 0.812 & 0.728 & $0.841-0.867$ \\
Organization memory & 0.762 & 0.680 & $0.786-0.835$ \\
Knowledge divergence & 0.710 & 0.637 & $0.772-0.817$ \\
Knowledge convergence & 0.755 & 0.672 & $0.801-0.844$ \\
\hline
\end{tabular}

\section{Results}

Table 9 presents the descriptive statistics and correlations among the variables. Team creative thinking, task complexity, participation guarantee, shared vision, social structural capital, and organization memory are positively correlated with knowledge divergence and knowledge convergence. Team knowledge heterogeneity is negatively correlated with knowledge convergence. Knowledge divergence is positively correlated with knowledge convergence. 
Table 9. Descriptive statistics of means, standard deviations, and correlations.

\begin{tabular}{|c|c|c|c|c|c|c|c|c|c|c|c|c|c|c|}
\hline Variables & $\mathbf{M}$ & SD & 1 & 2 & 3 & 4 & 5 & 6 & 7 & 8 & 9 & 10 & 11 & 12 \\
\hline 1. Gender & 1.55 & 0.50 & & & & & & & & & & & & \\
\hline 2. Age & 1.67 & 0.71 & $-0.11 *$ & & & & & & & & & & & \\
\hline 3. Size & 2.20 & 0.40 & $-0.18^{* * *}$ & $0.34 * * *$ & & & & & & & & & & \\
\hline 4. TKH & 2.65 & 0.76 & 0.03 & $0.15^{* *}$ & $0.10^{* * *}$ & $(0.89)$ & & & & & & & & \\
\hline 5. TCT & 4.02 & 0.61 & 0.03 & 0.03 & $-0.25^{* * *}$ & -0.05 & $(0.83)$ & & & & & & & \\
\hline 6. TC & 3.89 & 0.64 & -0.02 & 0.05 & 0.02 & 0.02 & $0.34^{* * *}$ & $(0.81)$ & & & & & & \\
\hline 7. PG & 4.25 & 0.49 & 0.05 & -0.04 & -0.14 ** & $-0.19^{* * *}$ & $0.60^{* * *}$ & $0.27 * * *$ & $(0.79)$ & & & & & \\
\hline 8. SV & 4.08 & 0.47 & -0.01 & 0.06 & $-0.18^{* * *}$ & $-0.13^{* *}$ & $0.57^{* * *}$ & $0.37^{* * *}$ & $0.62 * * *$ & $(0.80)$ & & & & \\
\hline 9. SSC & 3.66 & 0.68 & -0.04 & 0.04 & $0.12 * *$ & $0.08 * *$ & $0.23^{* * *}$ & $0.31 * * *$ & $0.15^{* * *}$ & $0.25^{* * *}$ & $(0.85)$ & & & \\
\hline 10. OM & 4.06 & 0.50 & 0.03 & $0.14 * *$ & 0.02 & -0.07 & $0.52 * * *$ & $0.47 * * *$ & $0.51 * * *$ & $0.51 * * *$ & $0.25^{* * *}$ & $(0.83)$ & & \\
\hline 11. KD & 4.11 & 0.49 & 0.10 * & 0.01 & $-0.14^{* *}$ & 0.08 & $0.52^{* * *}$ & $0.38^{* * *}$ & $0.56^{* * *}$ & $0.48^{* * *}$ & $0.34^{* * *}$ & $0.42^{* * *}$ & $(0.80)$ & \\
\hline 12. KC & 4.05 & 0.51 & -0.05 & $0.09 *$ & -0.08 & $-0.14 * *$ & $0.55^{* * *}$ & $0.43 * * *$ & $0.55^{* * *}$ & $0.63 * * *$ & $0.28^{* * *}$ & $0.56^{* * *}$ & $0.48^{* * *}$ & $(0.82)$ \\
\hline
\end{tabular}

Note: $\mathrm{M}$ is mean, $\mathrm{SD}$ is standard deviation, $\mathrm{N}=448 ;^{*} p<0.05,{ }^{* *} p<0.01,{ }^{* * *} p<0.001$, two-tailed. 
To test previous hypotheses, hierarchical regression analysis was employed. The arithmetic mean was used to characterize the variables with multiple items. Hypothesis testing results are shown in Table 10. In Model 1 , team knowledge heterogeneity $(\beta=0.10, p<0.001)$, team creative thinking $(\beta=0.12, p<0.05)$, task complexity $(\beta=0.11, p<0.05)$, participation guarantee $(\beta=0.37, p<0.001)$, social structural capital $(\beta=0.13, p<0.001)$ were significantly and positively related to knowledge divergence, thereby supporting $\mathrm{H} 2 \mathrm{a}, \mathrm{H} 3 \mathrm{a}, \mathrm{H} 4 \mathrm{a}, \mathrm{H} 5 \mathrm{a}$, and H7a. Shared vision $(\beta=0.37, n s)$ and organization memory $(\beta=0.03, n s)$ were not significantly related to knowledge divergence. Thus, H5a and H7a were not supported.

In Model 2, team knowledge heterogeneity $(\beta=-0.05, p<0.05)$ was negatively related to knowledge convergence. Team creative thinking $(\beta=0.11, p<0.05)$, task complexity $(\beta=0.11, p<0.05)$, participation guarantee $(\beta=0.14, p<0.05)$, shared vision $(\beta=0.37, p<0.001)$, social structural capital $(\beta=0.05, p<0.05)$ and organization memory $(\beta=0.19, p<0.001)$ were all significantly and positively related to knowledge convergence. Therefore, $\mathrm{H} 2 \mathrm{~b}, \mathrm{H} 3 \mathrm{~b}, \mathrm{H} 4 \mathrm{~b}, \mathrm{H} 5 \mathrm{~b}, \mathrm{H} 6 \mathrm{~b}, \mathrm{H} 7 \mathrm{~b}$, and $\mathrm{H} 8 \mathrm{~b}$ were supported. We test the relationship between knowledge divergence and knowledge convergence in Model 3. The regression coefficient between them was positive and significant, thereby supporting H1.

Table 10. Hierarchical regression analysis results.

\begin{tabular}{cccc}
\hline Variables & Model 1 & Model 2 & Model 3 \\
\hline & Knowledge divergence & Knowledge convergence & Knowledge convergence \\
\hline Team knowledge & $0.10^{* * *}$ & $-0.05^{*}$ & \\
heterogeneity & $0.12^{* *}$ & $0.11^{* *}$ & \\
Team creative thinking & $0.11^{* *}$ & $0.11^{* *}$ & \\
Task complexity & $0.37^{* * *}$ & $0.14^{* *}$ & \\
Participation guarantee & $0.07^{* * *}$ & $0.33^{* * *}$ & \\
Shared vision & $0.13^{* * *}$ & $0.05^{* *}$ & \\
Social structural capital & 0.03 & $0.19^{* * *}$ & \\
Organization memory & & & $0.50^{* * *}$ \\
Knowledge divergence & & & $-0.10^{*}$ \\
Knowledge convergence & 0.07 & -0.06 & $0.07 *$ \\
Gender & -0.002 & 0.04 & -0.08 \\
Age & -0.09 & -0.01 & $37.78^{* * *}$ \\
Size & $38.26^{* * *}$ & $50.27^{* * *}$ & 0.25 \\
F value & $0.47^{2}$ & 0.56 & 0.25 \\
$R^{2}$ & 0.46 & 0.52 & $0.23^{* * *}$ \\
Adjust $R^{2}$ & $0.44^{* * *}$ & $0.51^{* * *}$ & \\
$\Delta R^{2}$ & & &
\end{tabular}

Note: $\mathrm{N}=448 ;{ }^{*} p<0.05 ;{ }^{* *} p<0.01 ;{ }^{* * *} p<0.001$, two-tailed.

\section{Discussion and Conclusion}

\subsection{Discussion}

It can be seen from the results that team knowledge heterogeneity has different effects on knowledge divergence and knowledge convergence process. Consistent with the results reported in prior research $[26,86]$, in the process of knowledge divergence, different professional knowledge, skills, experience, etc. can promote members to generate more innovative ideas and help members to spread knowledge. In contrast, the knowledge heterogeneity may lead to contradictions and conflicts of members' opinions, so it is not conducive to the knowledge convergence process. This result is consistent with the prior research [87].

Inconsistent with previous research [70], the results show that shared vision has no significant positive impact on the knowledge divergence process. This study considers the following rational explanation. In the process of knowledge divergence, the team pays more attention to the creation of innovative ideas, and the opinions of members are often inconsistent. In the process of knowledge convergence, members can consider the overall goal of the team, reach consensus on key decisions and integrate innovative ideas. 
In addition, we can also see from the results that there is no significant positive impact between organization memory and knowledge divergence, which is not consistent with previous research [74]. In the process of knowledge divergence, if members are tied to the team's memory, only looking for the team's previous problem-solving processes and methods will hinder team members from knowledge divergence. In the process of knowledge convergence, the team's past knowledge, information, creativity, way of doing things, and patents will provide some clues and experiences for team members to integrate knowledge. Therefore, organizational memory is beneficial to the process of knowledge convergence.

In general, knowledge interaction in SIDRTs has different influencing factors than that in other teams, such as knowledge heterogeneity, task complexity and sustainability, participation guarantee, and social structural capital. For SIDRTs, differences in team members' expertise and skills can inspire members to generate more ideas, provide more innovative ideas to complete tasks and solve difficult problems. Task complexity and sustainability are also the unique influencing factors of knowledge interaction in SIDRTs. The more complex the tasks undertaken by the team, the more motivated the team members are to explore the problem. In addition, participation guarantee can create a free and relaxed environment for the team, to enhance the team's knowledge interaction effect. In addition, social structural capital helps team members to access internal and external resources of the team and obtain important information for knowledge interaction. It is worth noting that the key influencing factors identified by grounded theory are not common to other teams, and they are only for SIDRTs. However, for other teams, they are not necessary influencing factors of knowledge interaction and should be further analyzed.

\subsection{Theoretical Implicationsand Practical Implications}

The theoretical contributions related to knowledge interaction in SIDRTs are reflected by two aspects. First, we define the conception of knowledge interaction in SIDRTs from the complex system perspective, including elements, associations, environment, and emergence. Second, we are extending the literature on the knowledge interaction model. Though some literature holds the view that divergent idea generation must be followed by convergent idea selection for creativity to become innovation [88], there is no literature on integrating these two processes together. This research found that knowledge interaction mainly includes the process of knowledge divergence and knowledge convergence, and knowledge divergence positively affects knowledge convergence. Through the organic integration of knowledge divergence and knowledge convergence, interdisciplinary team members can better engage in knowledge interaction, and then solve complex and sustainable projects and achieve knowledge innovation.

In practical terms, our research also has some implications for understanding influencing factors of knowledge interaction for SIDRTs. First, for knowledge interaction object, our research results show that team knowledge heterogeneity has the opposite effect on knowledge divergence and knowledge convergence process. Hence, the interdisciplinary sustainability research team should focus on the selection of team members in order that the team knowledge heterogeneity is neither too large nor too small. Furthermore, it is necessary to continuously stimulate the creative thinking ability of individual, to realize the emergence of the team's overall creative thinking ability.

Second, our research results show that task complexity is positively related to knowledge interaction. Thus, the team should appropriately increase the complexity of the task, and then arouse the team members' enthusiasm and ability for exploring problems and solving problems. However, it is worth noting that due to the limitations of the sample size, we must consider that the capabilities of individual members are limited. Excessively complex tasks can cause serious blows to the overall morale of the team, resulting knowledge interaction not working normally.

Third, for knowledge interaction environment, SIDRTs should create a free, relaxed, trusting, and mutually understanding work environment that gives members a sense of security. In the process of knowledge interaction, team leader should encourage members to speak boldly and make reasonable 
guesses so that members can develop their strengths. In addition, ensure that the team members' personal goals are consistent with the team's goals, so that team members can be more fully engaged in knowledge interaction and achieve breakthroughs in innovation results.

Fourth, SIDRTs should broaden the social network within and outside the team so that members can keep up with the frontiers of research and can quickly find helpers when they encounter problems. On the other hand, according to the research results, organizational memory has no significant impact on the knowledge divergence and has a significant positive impact on the knowledge aggregation. Thus, while strengthening the organizational memory, the team should avoid team rigidity caused by the formation of mindset.

\subsection{Limitations and Future Research Issues}

Although this research studied on the influencing factors of knowledge interaction in SIDRTs systematically, there are still several limitations that will create interesting opportunities for further research avenues and agenda. First, in the section of grounded theory, this study used the remaining interview records from four SIDRTs randomly reserved to test whether the model has reached theoretical saturation. In future research, we can increase the number of our research teams and improve our model. Second, our samples were sufficiently representative of members of the SIDRT to support our findings, they can be generalized strictly only to SIDRTs in China. Future studies should sample a larger set of teams to confirm whether our results hold. Third, the research model only directly explored the influencing factors of knowledge interaction. In fact, knowledge interaction is a very complicated and inherently context-dependent phenomenon [89]. In future research, we can explore the role of the adjustment of knowledge interaction from the aspects of situational factors, such as environmental uncertainty, personnel uncertainty, and technical uncertainty. Finally, we can consider the experimental design approach to study the process of team knowledge interaction, and then artificially control some variables in future work.

Author Contributions: Conceptualization, Formal Analysis, Investigation, Resources, and Writing-Original Draft Preparation, Q.Z., W.P., and X.C.; Methodology, Software, Validation, Data Curation, Writing-Review and editing, Visualization, W.P., and X.C.; Supervision, Funding Acquisition, Q.Z.

Funding: This research was supported by (The National Natural Science Foundation of China) grant number (71573064, 71490724, 71273076) and (The Fundamental Research Funds for the Central Universities) grant number (3072019CFJ0904).

Conflicts of Interest: The authors declare no conflict of interest.

\section{References}

1. Ramaswami, A.; Weible, C.; Main, D.; Heikkila, T.; Siddiki, S.; Duvall, A.; Pattison, A.; Bernard, M. A Social-Ecological-Infrastructural systems framework for interdisciplinary study of sustainable city systems an integrative curriculum across seven major disciplines. J. Ind. Ecol. 2012, 16, 801-813. [CrossRef]

2. Bruno, M.C.; Siviglia, A. Assessing impacts of dam operations-Interdisciplinary approaches for sustainable regulated river management. River Res. Appl. 2012, 28, 675-677. [CrossRef]

3. Kim, S. Interdisciplinary approaches and methods for sustainable transformation and innovation. Sutainability 2015, 7, 3977-3983. [CrossRef]

4. Bettina, K.; Diehl, K.; Tscherning, K.; Helming, K. A framework for structuring interdisciplinary research management. Res. Policy 2013, 42, 26-272.

5. Memmott, R.J.; Marett, K.M.; Bott, R.L.; Duke, L. Use of the Neuman systems model for interdisciplinary teams. Online J. Rural Nurs. Health Care 2017, 1, 58-73.

6. Biox-x Standford University. Available online: https://biox.stanford.edu/about (accessed on 1 January 2018).

7. Hare, A.P. Handbook of Small Group Research, 2nd ed.; The Free Press: New York, NY, USA, 1976.

8. Rentsch, J.R.; Delise, L.A.; Mello, A.L.; Staniewicz, M.J. The integrative team knowledge building training strategy in distributed problem-solving teams. Small Group Res. 2014, 45, 568-591. [CrossRef] 
9. Paulus, P.B. Groups, teams, and creativity: The creative potential of idea-generating groups. Appl. Psychol. 2000, 49, 237-262. [CrossRef]

10. Chen, G.; Klimoski, R.J. The impact of expectations on newcomer performance in teams as mediated by work characteristics, social exchanges, and empowerment. Acad. Manag. J. 2003, 46, 591-607.

11. Kozlowski, S.W.J.; Ilgen, D.R. Enhancing the effectiveness of work groups and teams. Psychol. Sci. 2006, 7,77-124. [CrossRef]

12. Morgeson, F.P.; Reider, M.H.; Campion, M.A. Selecting individuals in team settings: The importance of social skills, personality characteristics, and teamwork knowledge. Pers. Psychol. 2005, 58, 583-611. [CrossRef]

13. Fay, D.; Borrill, C.; Amir, Z.; Haward, R.; West, M.A. Getting the most out of multidisciplinary teams: A multi-sample study of team innovation in health care. J. Occup. Organ. Psych. 2006, 79, 553-567. [CrossRef]

14. Jahn, T.; Bergmann, M.; Keil, F. Transdisciplinarity: Between mainstreaming and marginalization. Ecol. Econ. 2012, 79, 1-10. [CrossRef]

15. Truffer, B. Knowledge integration in transdisciplinary research project -the importance of reflexive interface management. GAIA 2007, 16, 41-45. [CrossRef]

16. Klein, J.T. Evaluation of interdisciplinary and transdisciplinary research-a literature review. Am. J. Prev. Med. 2008, 35S, S116-S123. [CrossRef] [PubMed]

17. Hampton, S.E.; Parker, J.N. Collaboration and productivity in scientific synthesis. Bioscience 2011, 61, 900-910. [CrossRef]

18. Klein, J.T. Interdisciplinarity: History, Theory and Practice; Wayne State University Press: Detroit, IL, USA, 1990.

19. Bammer, G. Integration and implementation sciences: Building a new specialization. Ecol. Soc. 2005, 10, 6. [CrossRef]

20. Hoffmann, S.; Pohl, C.; Hering, J.G. Methods and procedures of transdisciplinary knowledge integration: Empirical insights from four thematic synthesis processes. Ecol. Soc. 2017, 22, 27. [CrossRef]

21. Malone, T.W.; Crowston, K. The interdisciplinary study of coordination. Acm. Comput. Surv. 1994, 26, 87-119. [CrossRef]

22. Bronstein, L.R. A model for interdisciplinary collaboration. Soc. Work 2003, 48, 297-306. [CrossRef]

23. Edmondson, A.C. Speaking up in the operating room: How team leaders promote learning ininterdisciplinary action teams. J. Manag. Stud. 2003, 40, 1419-1452. [CrossRef]

24. Nancarrow, S.A.; Booth, A.; Ariss, S.; Smith, T.; Enderby, P.; Roots, A. Ten principles of good interdisciplinary team work. Hum. Resour. Health 2013, 11, 1-11. [CrossRef] [PubMed]

25. Lee, D.S.; Lee, K.C.; Seo, Y.W.; Choi, D.Y. An analysis of shared leadership, diversity, and team creativity inan e-learning environment. Comput. Hum. Behav. 2015, 42, 47-56. [CrossRef]

26. Rietzschel, E.F.; Nijstad, B.A.; Stroebe, W. Relative accessibility of domain knowledge and creativity:The effects of knowledge activation on the quantity and originality of generated ideas. J. Exp. Soc. Psychol. 2007, 43, 933-946. [CrossRef]

27. Dugosh, K.L.; Paulus, P.B.; Roland, E.J.; Yang, H.C. Cognitive stimulation in brainstorming. J. Personal. Soc. Psychol. 2000, 79, 722-735. [CrossRef]

28. Harvey, S.; Kou, C.Y. Collective engagement in creative tasks: The role of evaluation in the creative processin groups. Admin. Sci. Q. 2013, 58, 346-386. [CrossRef]

29. Rosenfield, P.L. The potential of transdisciplinary research for sustaining and extending linkages between the health and social sciences. Soc. Sci. Med. 1992, 35, 1343-1357. [CrossRef]

30. Bruce, A.; Lyall, C.; Tait, J.; Williams, R. Interdisciplinary integration in Europe: The case of the fifth framework programme. Futures 2004, 36, 457-470. [CrossRef]

31. Stokols, D.; Hall, K.L.; Taylor, B.K.; Moser, R.P. The science of team science-Overview of the field and introduction to the supplement. Am. J. Prev. Med. 2008, 35, S77-S89. [CrossRef]

32. Boerner, K.; Contractor, N.; Falk-Krzesinski, H.J.; Fiore, S.M.; Hall, K.L.; Keyton, J.; Spring, B.; Stokols, D.; Trochim, W.; Uzzi, B. A multi-level systems perspective for the science of team science. Sci. Transl. Med. 2010, 2. [CrossRef]

33. Shrum, W.; Genuth, J.; Chompalov, I. Structures of scientific collaboration. Phys. Today 2007, 61, 58-59.

34. Stipelman, B.; Feng, A.; Hall, K.; Moser, R.; Stokols, D.; Nebeling, L. The relationship between collaborative readiness and scientific productivity in the transdisciplinary research on energetics and cancer. Ann. Behav. Med. 2010, 391, 143. 
35. Cheng, X.; Zhang, Q. How to develop the interdisciplinary innovation teams sustainably? A simulation model from a perspective of knowledge fission and fusion. Sustainability 2018, 10, 3134. [CrossRef]

36. Mohammed, S.; Ferzandi, L.; Hamilton, K. Metaphor no more: A 15-year review of the team mental model construct. J. Manag. 2010, 36, 876-910. [CrossRef]

37. Klimoski, R.; Mohammed, S. Team mental model: Construct or metaphor? J. Manag. 1994, 20, $403-437$. [CrossRef]

38. Xuesen, Q.; Jingyuan, Y.; Ruwei, D. A new discipline of Science-The study of open complex giant system and its methodology. J. Syst. Eng. Electron 1993, 4, 2-12.

39. Marks, M.A.; Mathieu, J.E.; Zaccaro, S.J. A temporally based framework and taxonomy of team processes. Acad. Manag. Rev. 2001, 26, 356-376. [CrossRef]

40. Arrow, H.; McGrath, J.E.; Berdahl, J.L. Small Groups as Complex Systems: Formation, Coordination, Development, and Adaptation; Sage: Thousand Oaks, CA, USA, 2000.

41. Yue, X.; Dang, Y. The Effect of Personality on Team Performance: An Interpersonal Knowledge Interaction Perspective. In Proceedings of the IEEE International Conference on Software Quality, Prague, Czech Republic, 25-29 July 2017.

42. Zarraga, C.; Bonache, J. Assessing the team environment for knowledge sharing: An empirical analysis. Int. J. Hum. Resour. Man. 2003, 14, 1227-1245. [CrossRef]

43. Harada, T. Three steps in knowledge communication: The emergence of knowledge transformers. Res. Policy. 2003, 32, 1737-1751. [CrossRef]

44. Bryman, A. Integrating quantitative and qualitative research: How is it done? Qual. Res. 2006, 6, 97-113. [CrossRef]

45. Fetters, M.D.; Curry, L.A.; Creswell, J.W. Achieving integration in mixed methods Designs-Principles and practices. Health Serv. Res. 2013, 48, 2134-2156. [CrossRef]

46. Morse, J.M.; Niehaus, L. Mixed Methods Design: Principles and Procedures; Left Coast Press: Walnut Creek, CA, USA, 2009.

47. Creswell, J. Research Design: Qualitative, Quantitative, and Mixed Methods Approaches, 2nd ed.; Sage: Thousand Oaks, CA, USA, 2003.

48. Glaser, B.G.; Strauss, A. The Discovery of Grounded Theory: Strategies for Qualitative Research; Aldine: Chicago, IL, USA, 1967.

49. Mehta, A.; Mehta, N. Knowledge integration and team effectiveness: A team goal orientation approach. Decision Sci. 2018, 49, 445-486. [CrossRef]

50. Djenontin, I.N.S.; Meadow, A.M. The art of co-production of knowledge in environmental sciences and management: Lessons from international practice. Environ. Manag. 2018, 61, 885-903. [CrossRef] [PubMed]

51. Ribeiro, S.X.; Nagano, M.S. Elements influencing knowledge management in university-business-government collaboration: Case studies in national institutes of science and technology. Knowl. Proc. Manag. 2018, 25, 207-219. [CrossRef]

52. Fassinger, R.E. Paradigms, praxis, problems, and promise: Grounded theory in counseling psychology research. J. Couns. Psychol. 2005, 52, 156-166. [CrossRef]

53. Strauss, A.; Corbin, J. Basics of Qualitative Research: Techniques and Procedures for Developing Grounded Theory, 2nd ed.; Sage: Thousand Oaks, CA, USA, 1998.

54. Moran, P.; Ghoshal, S. Theories of economic organization: The case for realism and balance. Acad. Manag. Rev. 1996, 21, 58-72. [CrossRef]

55. Harvey, S. A different perspective: The multiple effects of deep level diversity on group creativity. J. Exp. Soc. Psychol. 2013, 49, 822-832. [CrossRef]

56. Dougherty, D. Interpretive barriers to successful product innovation in large firms. Organ. Sci. 1992, 3, 179-202. [CrossRef]

57. Nemeth, C.J. Differential contributions of majority and minority influence. Psychol. Rev. 1986, 93, 23-32. [CrossRef]

58. Ward, T.B. Cognition, creativity, and entrepreneurship. J. Bus. Ventur. 2004, 19, 173-188. [CrossRef]

59. Nickerson, J.A.; Zenger, T.R. A knowledge-based theory of the firm-the problem-solving perspective. Organ. Sci. 2004, 15, 617-632. [CrossRef]

60. Tierney, P.; Farmer, S.M. Creative self-efficacy: Its potential antecedents and relationship to creative performance. Acad. Manag. J. 2002, 45, 1137-1148. 
61. Coelho, F.; Augusto, M. Job characteristics and the creativity of frontline service employees. J. Serv. Res. 2010, 13, 426-438. [CrossRef]

62. Chae, S.; Seo, Y.; Lee, K.C. Effects of task complexity on individual creativity through knowledge interaction: A comparison of temporary and permanent teams. Comput. Hum. Behav. 2015, 42, 138-148. [CrossRef]

63. Joshi, A.; Pandey, N.; Han, G.H. Bracketing team boundary spanning: An examination of task-based, team-level, and contextual antecedents. J. Organ. Behav. 2009, 30, 731-759. [CrossRef]

64. Hulsheger, U.R.; Anderson, N.; Salgado, J.F. Team-level predictors of innovation at work: A comprehensive meta-analysis spanning three decades of research. J. Appl. Psychol. 2009, 94, 1128-1145. [CrossRef] [PubMed]

65. Kerr, N.L.; Bruun, S.E. Dispensability of member effort and group motivation losses: Free-rider effects. J. Pers. Soc. Psychol. 1983, 44, 78-94. [CrossRef]

66. Gonzalez-Roma, V.; Fortes-Ferreira, L.; Peiro, J.M. Team climate, climate strength and team performance. A longitudinal study. J. Occup. Organ. Psych. 2009, 82, 511-536. [CrossRef]

67. Ancona, D.G. Outward bound: Strategies for team survival in an organization. Acad. Manag. J. 1990, 33, 334-365. [CrossRef]

68. Hofhuis, J.; Mensen, M.; Ten Den, L.M.; Van den Berg, A.M.; Koopman-Draijer, M.; Van Tilburg, M.C.; Smits, C.H.M.; De Vries, S. Does functional diversity increase effectiveness of community care teams? The moderating role of shared vision, interaction frequency, and team reflexivity. J. Appl. Soc. Psychol. 2018, 48, 535-548. [CrossRef]

69. Peltokorpi, V.; Yamao, S. Corporate language proficiency in reverse knowledge transfer: A moderated mediation model of shared vision and communication frequency. J. World Bus. 2017, 52, 404-416. [CrossRef]

70. Pearce, C.L.; Ensley, M.D. A reciprocal and longitudinal investigation of the innovation process: The central role of shared vision in product and process innovation teams (PPITs). J. Organ. Behav. 2004, 25, 259-278. [CrossRef]

71. Nahapiet, J.; Ghoshal, S. Social capital, intellectual capital, and the organizational advantage. Acad. Manag. Rev. 1998, 23, 242-266. [CrossRef]

72. Patrashkova-Volzdoska, R.R.; McComb, S.A.; Green, S.G.; Compton, W.D. Examining a curvilinear relationship between communication frequency and team performance in cross-functional project teams. IEEE T. Eng. Manag. 2003, 50, 262-269. [CrossRef]

73. Robert, L.P.; Dennis, A.R.; Ahuja, M.K. Social capital and knowledge integration in digitally enabled teams. Inform. Syst. Res. 2008, 19, 314-334. [CrossRef]

74. Mol, M.J.; Birkinshaw, J. The sources of management innovation: When firms introduce new management practices. J. Bus. Res. 2009, 62, 1269-1280. [CrossRef]

75. Prahalad, C.K.; Hamel, G. The core competence of the corporation. Harvard Bus. Rev. 1990, 90, 79-91.

76. Duncan, R.; Weiss, A. Organizational Learning: Implications for Organizational Design. In Research in Organizational Behavior: An Annual Series of Analytical Essays and Critical Reviews; Elsevier: Amsterdam, The Netherlands, 1979; pp. 75-123.

77. Tortoriello, M.; McEvily, B.; Krackhardt, D. Being a catalyst of innovation: The role of knowledge diversity and network closure. Organ. Sci. 2015, 26, 423-438. [CrossRef]

78. Jiang, H.; Zhang, Q. Development and validation of team creativity measures: A complex systems perspective. Creat. Innov. Manag. 2014, 23, 264-275. [CrossRef]

79. Campbell, D.J. Task complexity: A review and analysis. Acad. Manag. Rev. 1988, 13, 40-52. [CrossRef]

80. Anderson, N.; West, M.A. The team climate inventory: Development of the TCI and its applications in team building for innovativeness. Eur. J. Work Organ. Psychol. 1996, 5, 53-66. [CrossRef]

81. Jianglin, K.; Shitao, J.; Jianmin, S. Research on team social capital dimension development and structure testing. Stud. Sci. Sci. 2007, 5, 935-940.

82. Hanvanich, S.; Sivakumar, K.; Hult, G.T.M. The relationship of learning and memory with organizational performance: The moderating role of turbulence. J. Acad. Market. Sci. 2006, 34, 600-612. [CrossRef]

83. Camison, C.; Villar-Lopez, A. Non-technical innovation: Organizational memory and learning capabilities as antecedent factors with effects on sustained competitive advantage. Ind. Mark. Manag. 2011, 40, 1294-1304. [CrossRef]

84. Bock, G.W.; Zmud, R.W.; Kim, Y.G.; Lee, J.N. Behavioral intention formation in knowledge sharing: Examining the roles of extrinsic motivators, social-psychological forces, and organizational climate. MIS Quart. 2005, 29, 87-111. [CrossRef] 
85. Podsakoff, P.M.; MacKenzie, S.B.; Lee, J.Y.; Podsakoff, N.P. Common method biases in behavioral research: A critical review of the literature and recommended remedies. J. Appl. Psychol. 2003, 88, 879-903. [CrossRef]

86. Wu, D.; Liao, Z.; Dai, J. Knowledge heterogeneity and team knowledge sharing as moderated by internal social capital. Soc. Behav. Personal. 2015, 43, 423-436. [CrossRef]

87. Tsai, F. Knowledge heterogeneity, social capital, and organizational innovation. J. Organ. Change. Manag. 2018, 31, 304-322. [CrossRef]

88. Rietzschel, E.F.; Nijstad, B.A.; Stroebe, W. Productivity is not enough: A comparison of interactive and nominal brainstorming groups on idea generation and selection. J. Exp. Soc. Psychol. 2006, 42, 244-251. [CrossRef]

89. Chua, A.Y.K.; Goh, D.H. Untying the knot of knowledge management measurement: A study of six public service agencies in Singapore. J. Inf. Sci. 2008, 34, 259-274. [CrossRef]

(C) 2019 by the authors. Licensee MDPI, Basel, Switzerland. This article is an open access article distributed under the terms and conditions of the Creative Commons Attribution (CC BY) license (http://creativecommons.org/licenses/by/4.0/). 